\title{
CONCEPTUAL FRAMEWORK REGARDING THE INFLUENCE OF AUDIT MISSION'S MANAGEMENT OVER HUMAN RESOURCES AUDIT
}

\author{
Alice STEFANESCU ${ }^{a *}$, Irinel MARIN ${ }^{b}$ \\ ${ }^{a},{ }^{b}$ Bucharest University of Economic Studies, Romania
}

DOI: $10.24818 / \mathrm{IMC} / 2020 / 04.15$

\begin{abstract}
Human resources management has experienced significant development in recent years, while the concept of audit has become more and more refined, naturally reaching the creation of an independent field with specific methods and techniques. Employees are resources that must be trained and developed, for which investments must be made, since human resources are the first strategic resources of the organization. The human resources audit evaluates the activity of human resources in an organization in order to improve it, and brings the human resources to operate at the standards imposed by the entity's management.

This paper explores some of the available frameworks and professional principles that auditors can use as guidance tools to integrate in their work in order to improve the processes of auditing and weighs the influence that the management of the audit mission has on the human resources audit. The article also describes some applications of human resources audit to human resources management.
\end{abstract}

KEYWORDS: audit mission, framework, human capital, human resources audit, professional principles, resource management.

\section{INTRODUCTION}

Competitive human resources management is essential for the success of any economic entity. For this reason, it is necessary to make an analysis, a thorough control of the review of problems in the context of a given entity and everything related to them, as to discover the determinants in order to facilitate the amelioration or complete reduction of "serious diseases" that affect the "health" of the organization.

Human resource expenditures are strategic investments and must be treated as such. In order to maximize efficiency, the audit of human resources must be carried out acknowledging certain key aspects, for which the use of conceptual frameworks is of tangible help. They provide a scaffolding on which the mission of audit can be built and ensure that effective measures can be achieved.

\section{MANUSCRIPT}

\subsection{The concept of human resources audit}

Auditing is a technique for investigating functionality and compliance of a process or project, which is relatively new in the inventory of methods and techniques available to specialists. It is a manner/approach of research that starts from predetermined objectives, based on a system of criteria, and allows the auditor to issue an independent and qualified opinion, with the possibility of formulating recommendations regarding the functionality and/or compliance of the studied

\footnotetext{
* Corresponding author. E-mail address: alicestefanescu@yahoo.com
} 
processes. Its defining characteristics are the coherence and homogeneity of the actions undertaken, the repetitiveness, the normalization of the working methods, and the independence of the auditor. Specialists in the field often argue that auditing is a specific approach that should not be confused with a number of other techniques for investigating the direction of organizations and economic and social structures: expertise, controls, studies, mediation, inspection, etc. The audit is a particular way of knowing the internal reality of the audited entity, based on common ex-post study procedures, but also on some specific procedures, starting with direct observation of acts and facts, diagrams, statistical calculations, compliance tests, questioning (written or oral), etc.

The audit is not a ruling. It does not lead to the expression of a favorable or unfavorable opinion regarding a situation, a reality, etc. Auditors work with a comprehensive database on the situations analyzed, built on tangible facts and evidence, which will lead to the identification of the objective audit criteria.

The audit is considered to be an essential tool for achieving the objectives of the organization. The main purpose of the audit is to assess non-conformities in relation to the regulations in force and to outline the necessary actions to eliminate these non-compliances. The audit consultancy is completed by an audit report, which is elaborated following a complex process.

It should be noted that any organization that needs to conduct audits must implement and conduct an effective audit program.

The purpose of the audit program is to plan the type and number of audits and to identify and provide the necessary resources to perform them.

The audit mission may include audits with a variety of objectives. Depending on the size, nature, and complexity of the organization to be audited, the audit program may include one, several or more audits and also joint or combined audits.

\subsection{The plan-do-check-act cycle}

The PDCA cycle - also known as the Deming cycle - was first named in the 1930s by Walter Shewhart, who discussed this concept in his book „Statistical Method from the Viewpoint of Quality Control”. This concept was later adopted by W. Edwards Deming, one of the most wellknown Quality Managers in the world at the time. This model provides a framework for improving a process or system. It can be used as a guidance tool throughout the improvement project or for the development of specific projects when areas in need of improvement have been identified.

Figure 1 illustrates the application of the PDCA cycle - Plan-Do-Check-Act - conducting an audit program regardless of its nature, a program that can be successfully applied in the management of human resources audits.

\section{Plan}

An opportunity is recognized and a change is planned. In this phase, we must first analyze what can be improved, looking for those areas that present opportunities for change. Planning must be done with a conducted effort. Failure to plan and prevent problems will result in a loss of human, material, technological, and time resources. This failure will increase the cost of the system without adding value. Moreover, the customer is not always willing to pay for these losses. The inevitable result will be a loss of market share.

\section{Do}

Once the change has been planned, we are proceeding to its fulfillment. It is preferable, in situations where this is possible, to do so on a smaller scale first, in order to be able to prevent and correct any inaccuracies. To say that "everyone has to do their 'job' as best they can" is certainly not a solution. Sometimes drastic changes are needed and the first thing to learn is how to accomplish a shift. Edwards Deming has created a very useful set of recommendations that can be used for this. 


\section{Check}

What has been achieved through the change made? What didn't work? Here are just two of the questions that can be asked at this crucial stage of the PDCA cycle. Once the change has been implemented for a while, it will be needed to determine how well it works. Did the implemented change really lead to what was wanted? The most important thing is to determine which of the system parameters need to be measured and how often they need to be measured in order to properly monitor the level of change. This information is extremely useful, as shown by the last stage of the cycle (Figure 1).

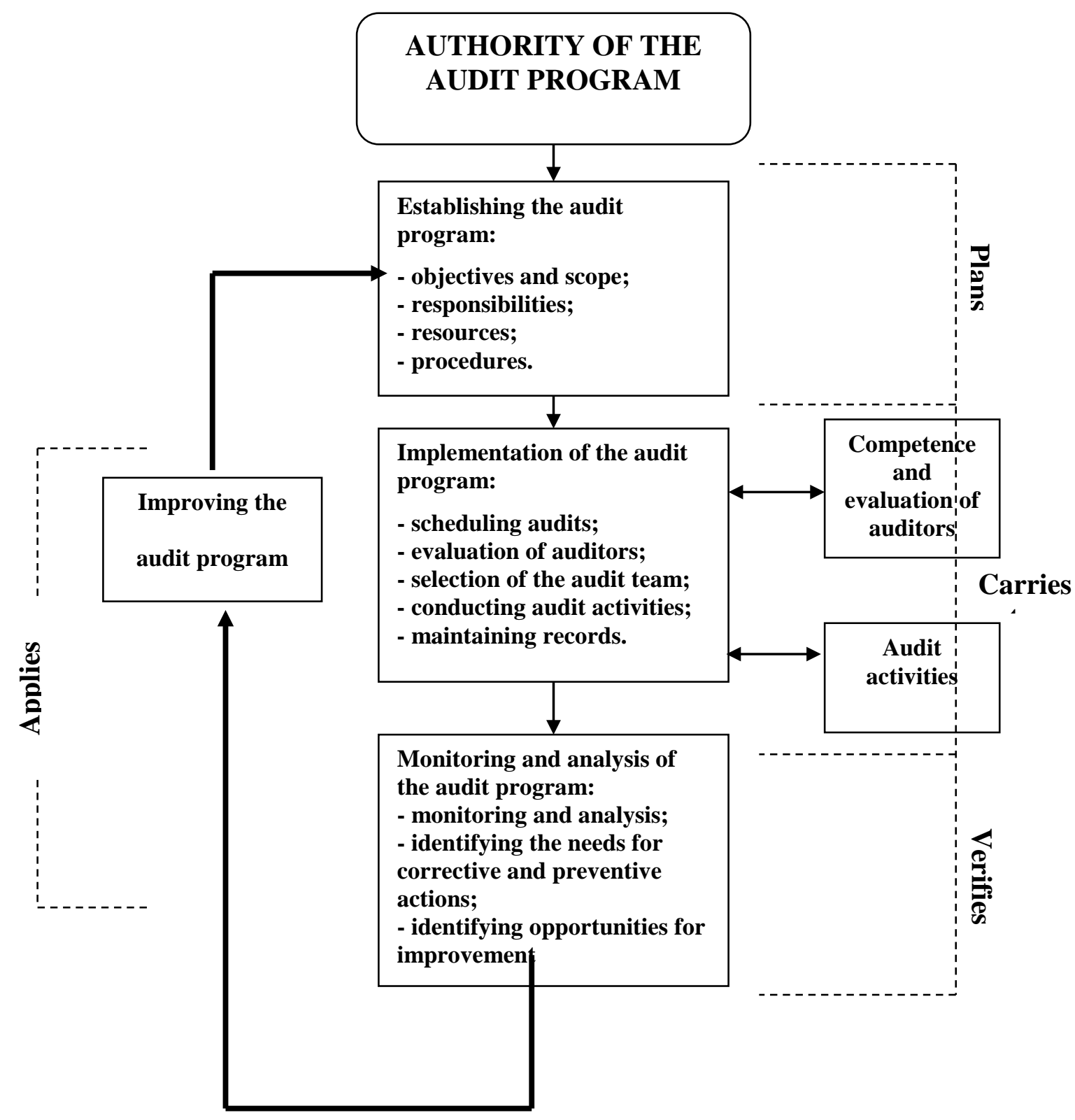

Figure 1. Illustration of the process flow for the management of an audit mission

Source: Adapted from European Committee for Standardization (2002)

Act - to adopt the change definitively, to abandon or to resume the cycle.

After the change has been planned, implemented, and then monitored, a decision must be made on whether it is still worth applying it. If the change has taken up too much time, proved difficult to integrate into the system, or has not even led to the expected improvement, it is possible to make the 
choice to give it up or devise a different one. If, on the other hand, the change has led to a considerable improvement or a significant effect, it may be considered necessary to continue it (even in a more complex context), or to expand the test area. These decisions refer again to the first stage of the cycle, where a new solution for improvement is likely to be found.

\subsection{Professional principles of auditing}

Auditing is a complex process, and any auditor or audit entity must adhere to certain professional principles. Among the main principles to be observed in the audit mission program we list:

1. The principle of professionalism. It is the essential element of the audit process and is represented by the aptitudes needed to perform the specific tasks of the audit. Auditors must be specialists in the areas in which they carry out audit activities. For example, not every human resource specialist can perform audit exercises. Auditors are people who specialize in the areas they audit and have all the skills necessary to perform the audit.

2. Another necessity of the audit mission is independence. Clearly, the principle of independence is one of the most important principles of the whole audit process. The audit entity and the auditor should be independent of the audited entity so as to objectively collect and analyze data about its activities and present the best solutions for its profile and situation. Usually, the audit entity is changed after three to five years of continuous collaboration.

3. The principle of source identification refers to the fact that for any information collected during the audit processes it is necessary for the source to be identifiable and valid. This ties into the idea that the information must be relevant to the audit objectives.

4. Regularity. The results of the audit become more relevant when compared to the results of previous years. In this way, auditors can determine whether the organization has succeeded in improving its situation or not.

5. Confidentiality is also one of the essential components of all missions of audit. In common practice, the work of an auditor is also regulated by the confidentiality clauses present in the audit contract. But beyond this formal obligation, auditors believe that their professionalism depends on the confidentiality with which they exercise their tasks.

6. All this cannot go without mention of the particularly important principle of compliance with the law. Some categories of audit are regulated either by national laws and regulations or by professional standards. The auditor's work must always follow these rules and standards.

\subsection{Influence of audit mission's management over human resources audit}

We can see that in recent decades, the concept of audit has become more and more refined, naturally reaching the creation of an independent field, with its own objectives but also with specific methods and techniques whose use ensures the achievement of objectives.

"The management audit can be defined as an expert and independent research system meant to highlight the evidence which, compared to a pre-established reference system, allows the formulation of findings on which a qualified opinion is based (in terms of materiality and specific risk), to a reasonable assurance (attestation/certification/validation) in relation to the quality, level of performance and/or functionality of the investigated management entity" (Nicolescu \& Zecheru, 2003).

In support of this definition, the Romanian authors Ovidiu Nicolescu and Vasile Zecheru, come with a graphic representation (figure 2) of the relationship between the evidence, the reference system and the results of the investigation, also called the "golden triangle" of the audit. This is the fundamental mechanism of any audit process. 


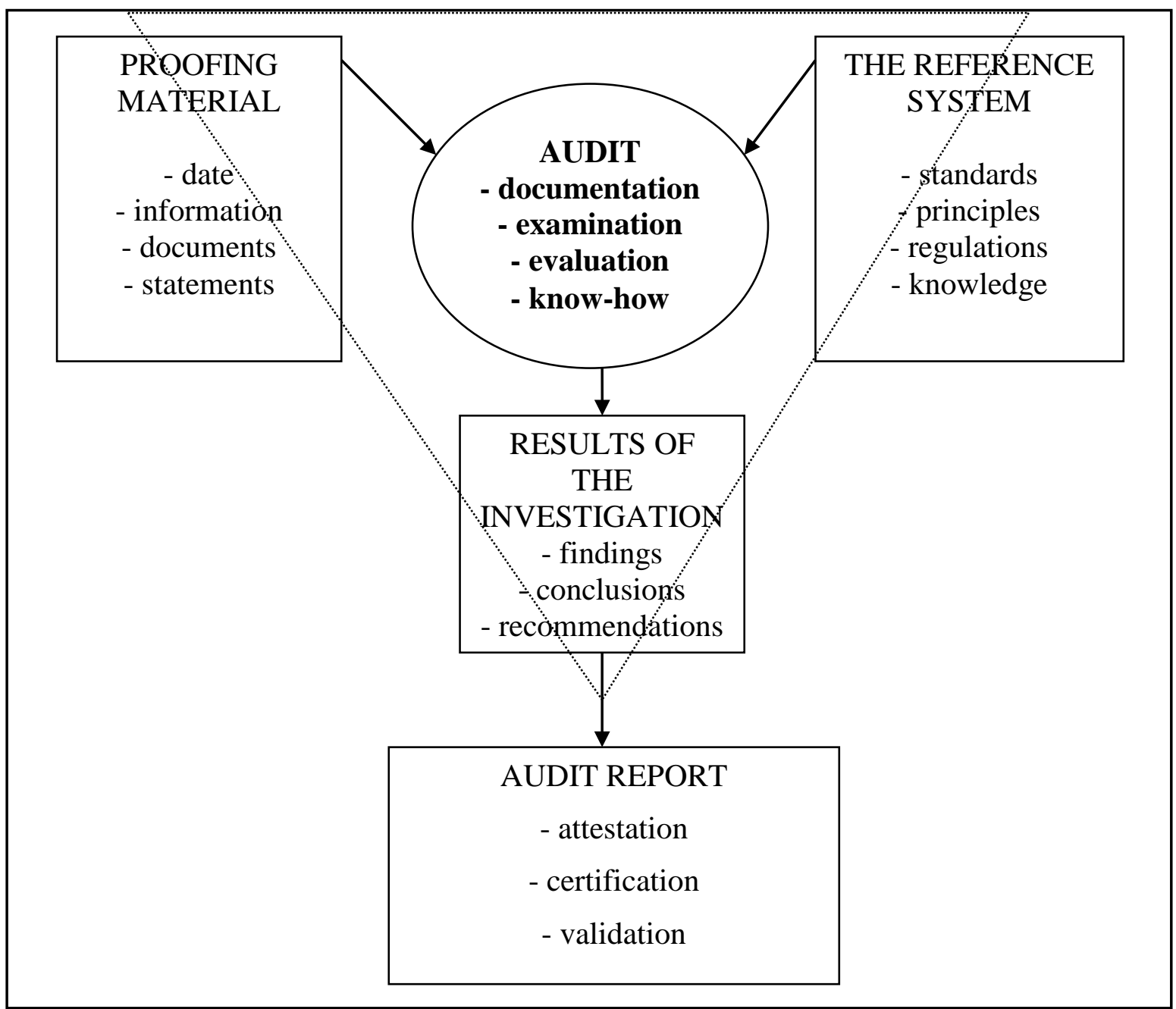

Figure 2. The "golden triangle" of auditing

Source: adapted from Nicolescu \& Zecheru (2003)

Practicing the management audit therefore always means, regardless of the definition, the observation of the form and not of the content.

In human resources management, the old practices based on responsibilities and authority are replaced by practices that place an increasing emphasis on the development of individuals as active and cooperating members of the team. Specialists have demonstrated the increased importance of experience and continuity of work in the field of human resources for both people and the entity. The human resources audit helps to operate at the standards imposed by the entity's management and to implement corrective or improvement measures up to the last level in the company's organizational chart.

Labor organizations can be seen as socio-economic systems in which, by combining the factors of production (human, financial, material, and informational resources), the production of goods and services takes place in order to obtain a profit (Peretti, 1990)

By a broad definition, organizations are associations of people formed to achieve a common goal. In order to exist, any organization is built on interactions between individuals who pursue the same objectives. The fundamental argument for the emergence of organizations is the limited nature of human physical and intellectual abilities, but also the fact that man is par excellence a social being. 
The social aspect is also strengthened by the meaning that Gary Johns (1996) gives to organizations. In his opinion, organizations are social inventions designed to achieve common goals through a group effort. This means that we are dealing with a coordinated presence of people, that individuals are grouped in organizations for a purpose that can only be achieved on the basis of a group effort, based on formal and informal interactions.

Within human resources management, all elements, aspects, and behaviors related to it must be periodically audited and evaluated. Some of the advantages of human resources auditing are:

- identifies the contributions of the human resources department in the company;

- improves the professional image of the human resources department;

- discovers critical human resources issues;

- reduces human resources costs through more efficient staffing procedures.

A recent study based on the example of several Canadian companies shows that two-thirds of managers surveyed consider "human resource spending" a strategic investment and not just costs that need to be minimized (Belcourt et al., 2008).

The human resources audit aims to understand this dynamic and how human capital activities are managed in order to identify possible dysfunctions, to analyze the performance of human resources departments and to promote quality management standards in this field.

Hence, the concept of human resources is not new. In his book The Practice of Management, republished in 2002 by Butterworth-Heinemann, P. Drucker assigned management three functions: achieving economic performance, leading managers, and managing workers. "Man is the only resource that can be developed that is available to man," he said, and "we must consider people as resources [...] managers and workers together represent the human resources of an organization."

Only by considering all the facets that define the human personality, abilities, knowledge, aspirations, temperament, and character traits, management can carry out managing the most precious resource, the only resource endowed with the ability to know and overcome its own limits (Ionescu, 1996).

It can be established that human resource is a strategic resource and, along with the financial resource within an organization, it is of paramount importance.

C. H. Besseyre-Horts argues that employees are resources that must be trained and developed, for which investments must be made, and states that "human resources are the first strategic resources of the organization." (Peretti, 1997)

That is why it is necessary that these investments and expenses have as a purpose the development and success of the organization, along with obtaining a competitive advantage. The traditional attitude towards the workforce is to treat human resources, the people in an organization, as an expense or, if we look at the accounting approach to the concept, as an element of human resources. (Milokovich \& Bourdeau, 1991). From this perspective, staff costs are considered "maintenance and use" of human resources that must be minimized and recovered as soon as possible (Manolescu, 2003).

The human resources audit aims to verify the company's compliance with its obligations, in order to ensure, for example, continuous and effective training to develop the knowledge base for the individual, which brings profit primarily to the employer (Odegov \& Niconova, 2004).

Well-known authors in the field of human resource management, Stettler and Collins, stated that "a human resource audit actually means a review and a meeting, or an audition before conducting an evaluation or assessment." (Ruffino, 2011) 
In 2000, French author Ingalens suggested that "the human resources audit is a judgment on the quality of an organization's human resources”, while in his paper, Bill Coy argues: "The audit of human resources is a process of policies, procedures, documentation, systems and research practices regarding the functions of human resources in the organization" (Coy, 2002).

The human resources audit demonstrates how much the human system contributes to labor productivity and organizational effectiveness as a whole. (Nguwi, 2003). Relying solely on the work of the human resources department and managers, on one's own assessment of human resource status, can be too risky. The human resources manager is in turn part of the organization and is influenced by it. Relationships with other members of the company may be under the sign of antipathy or sympathy, while uncertainty generated by a possible crisis can lead him to superficial or erroneous conclusions. Primarily, it is about the subjectivity with which the organization is analyzed. On the other hand, solely the financial and accounting reports, those that refer to the assets of the organization, are not enough to create a clear and comprehensive picture of the organization. Sometimes there are great dangers behind the disastrous situation of human resources. Thus, a careful audit and a report in this regard can avoid or anticipate a multitude of subsequent problems. In support of these statements we can add the conclusions formulated by Irinel Marin (2011) in the book Human Resources Audit.

The human resources audit is an activity carried out by professionals inside or outside the organization, human resources professionals, who collect and evaluate evidence related to the human resources management system within the organization, in order to express an independent opinion on the comparison between the observed and the pre-established ones, related to the observance and application of a previously defined quality criterion.

In support of this view, the author of this definition starts from the premise that the concepts of audit in general and human resources audit in particular, establish a unitary and coherent set of elements designed to determine and ensure the highlighting of evidence and the delivery of the most significant findings regarding the studied entity, on the basis of which, with the help of specific methods and techniques, the qualified opinion can be expressed (the auditor's conclusions and recommendations).

As a result, the basic idea that concerns us in formulating a model in the field is that the human resources audit evaluates the activity of human resources in an organization in order to improve it. The human resources audit provides feedback on the human resources function and on how the activities of this function are carried out.

\section{CONCLUSIONS}

The influence of the management of the audit mission on the audit of human resources is a topic worthy of wider debate. Human resources are the main asset of any organization and auditing is an essential component in maintaining the „health” of the human resources department and the organization as a whole.

The use of frameworks helps to streamline audit processes and identify the measures that are truly useful in solving the discovered problems, by continuously referring back to the original concerns and keeping the auditing a dynamic process, with the aim of improving productivity and effectiveness of the organization as a whole. 


\section{REFERENCES}

Belcourt, M., Bohlander, G., \& Snell, S. (2008). Managing Human Resources (5th Canadian ed.). Torento: Thomson-Nelson.

Coy, B. (2002). Introduction to the Human Resources Audit. L Piana Associates, Inc.

Ingalens, J. (2000). Audit des Ressources Humaines. Paris: Éd. Liaisons.

Ionescu, G., G. (1996). Dimensiunile culturale ale managementului. Bucharest: Editura Economică. Johns, G. (1996). Organizational Behavior. HarperCollins College Publisher.

Manolescu, A. (2003). Managementul Resurselor Umane, Ediţia a patra. Bucharest: Editura Economică.

Marin, I. (2011). Auditul Resurselor Umane. Bucharest: Editura Economica.

Milokovich, G., T. \& Bourdeau, J., W. (1991). Human Resource Management, Sixth Edition. Boston: Irwin Boston.

Nicolescu, O. \& Zecheru, V. (2003). Auditul managementului în instituţia publică. Bucharest: Editura Tribuna Economică.

Nguwi, M. (2003). How to Carry Out A Human Resources Audit, USA.

Odegov, I., G. \& Niconova, T., V. (2004). Auditul Personalului. Moscow: Ed. Examen.

Peretti, J., M. (1990). Gestion des resources humaines. Paris: Ed. Vuipert - Gestion.

Peretti, J., M. (1997). Resources humaines. Paris: Edition Vuibert-Gestion.

Ruffino, S., F. (2001). Introduction to the Human Resources Audit. Lorman Education Services. 